and left phrenic nerves were traced lying upon and at one part just imbedded in the tumour. The left vagus was traced backwards towards the left bronchus, imbedded, to a considerable extent, in the tumour; the nerve appeared healthy, though stretched, and donbtless somewhat compressed by the tumour. The right pleural sac was filled with transparent lemoncoloured serum. The lung tissue proper, liver, and spleen, were healthy. A very small cancerous tumour occupied the right lidney; the other was apparently healthy. There was no opportunity of examining the heal. Microscopic examina tion revealed the elements characterising malignant growth.

REuarks. Upon analysing this most instructive case, we are led to the consideration of the several pathologic conditions with which it might, in transitu, have been confounded. The initial phenomena were, apparently, those which indicated simple change of the normal constitution of the blood,--pallor, breathlessness upon exertion, puffiness beneath the eyelids, vertigo, quickened pulse, debility. These symptoms were gradually followed by considerable œdema of the face; increasing pallor; constant and severe lumbar pain preventing sleep; headache; deafness; pain in the chest, interscapular region, etc.; tender submaxillary glands,-symptoms which, in their aggregate, naturally sugrrested that the kidney might be the seat of some degenerative process. Careful examination of the urine, however, lent no confirmation to this view, inasmuch as the quantity of urine passed was normal, as also its specific gravity; it was, besides, free from albumen or other visible abnormal element; the lumbar pain, also, soon ceased, suddenly and permanently. Coincident with, or immediately successive to the symptoms already recorled, there supervened cough, attended with scanty expectoration of frothy, and occasionally of muco-sanguineous sputa; thirst; white tongue; swollen and ulcorated tonsils; increasing speed of pulse; neculiar cracked voice. In addition to the great œedema of the face, the ankles became slightly œdematous. Physical examination, which at first yielded no results, now revealed marked dulness of the superior sternal region, which gradually extended over the entire right half of the chest; cessation of the respiratory murmur: ægophony. In this phase of the case what did such physical signs import? Aneurism of the thoracic aorta, with secondary pleuritic effusion? The marked œdema of the face and, in a less degree, of the ankles, the cracked voice, early situation of percussion dulness, character of the congh and sputa, certainly favoured, to some extent the idea of possible aneurismal pressure upon the bronchial tubes and large venous trunks, the latter result inducing the cerebral phenomena alluded to. Still, the early history of the case, the age of the patient, the association and succession of the symptoms, together with the absence of tumour, abnormal impulse or murmur, were scarcely reconcilable with the hypothesis of aneurism.

Could the occurrence of tubercular deposit better explain the observed phenomena? The premonitory symptoms were not dissimilar to those of tubercular dyscrasia; and even at a later phase, some of the signs, and some of the symptoms especially, were not opposed to such disease,-the pleuritic effusion being the possible result of tubercular irritation; still, as on the hypothesis of aneurism, there were residual phenomena which were excluded from, and others wanting which should have been included in, the definition of tuberculous disease. Such were the doubts involved in the very nature of the case, so that a satisfactory diagnosis seemed scarcely possible until the appearance of the external tumours; then the suspicion of malignant disease was at once originated, - such disease affording a sufficient explanation of the hitherto anomalous symptoms.

From this, and many other cases recorded by different observers, the great semiotical value of external tumour occurring in the course of obscure thoracic disease, is strikingly $\mathrm{ex}$ emplified. Indeed, so great is the value of the sign, that, in the cases named, such tumours should be carefully searched for, and if discovered and determined to be of recent origin, it would probably justify the observer in at once including the case in the category of malignant disease. The widely spread pain, as also the inutility of treatment, are additional points of value in the diagnosis of this class of diseases.

With regard to the lumbar pain, it is worthy of note, that this symptom was apparently limited to the period of actual renal deposit, and definitely ceased with the completion of the process and its extension to, and increase in, more remote organs.

\section{CASES OF DEATH WITH AIR IN THE VEINS.}

By George May, jun., Esq., Reading.

CASE I. On December 15th, 1855, I assisted Mr. Walford at the post mortem examination of Mrs. H., aged 50, who had died the day previous. She had long been ailing, having complained chiefly of spasms in the bowels, especially on the right side; and for a fortnight before her death, she suffered from pain in the throat. She was rather hoarse; but there was no tenderness on pressure. Her abdomen was large, and the veins were distinct; the liver was much enlarged; and the urine was of low specific gravity and albuminous. Although a grave opinion was entertained of her case, neither a speedy nor abrupt termination was expected. She was seen by Mr. Walford at 1 p.M. on the day of her death, and found to be sinking. Her abdomen was tense, and extremely sensitive to pressure respiration was thoracic; the pulse was feeble and running. She died in the evening.

The next afternoon the body was examined. There was much thickening of the colon, with ulceration of the cæecun and ileo-crecal valve. There was air in the adjacent subperitoneal tissue, which we traced upwards to the diaphragm and downwards for some distance; it also extended between the muscles of the parictes. There was frothy blood in the heart and in the portal and pulmonary veins. Air-bubbles were also seen in the submucous cellular tissue of the intestine, near the ulcer. The kidneys were very large.

It was not known that there had been any hamorrhage from the bowel, and no open vessel could be discovered on inspection of the intestine. The uterus was much enlarged, and contained a fibrous tumour.

Renarks. What was the cause of death? The symptoms were those of perforation; and it is well known that empliysema may follow wounds of the intestine; but the ulcer opened into the mesocrcum, and we could not detect any escape of the contents of the bowel into the abdomen. Would subperitoneal emphysema cause thoracic respiration?

Air was traced from the ulcer through the liver to the heart. How did it enter the veins? There had not been any hrmorrhage, and no open vessel could be detected. Was the air produced by the ulceration? We shall see in a subsequent case that air may be locally generated. Small quantities of air may enter the circulation, without producing much effect, especially if it enters slowly.

CASE II. Miss $H$., aged 42 , but looking much older, and being of a very spare habit of body, had usually enjoyed good health, with the exception of occasional attacks of bilious vomiting. She had been suffering from one of her usual ail ments for three or four days before her death; but, although I was in attendance at the house, she did not think it necessary to obtain my advice.

On the morning of March 9th, 1857, after violent vomiting, she became suddenly faint. On my arrival, I found her covered with a cold perspiration; her face was pale and anxious; the lips and hands being livid. The respiration was very short and hurried; the pulse frequent, small, and very feeble; the heart was acting tumultuously, but I could not hear any churning sound, nor could I distinguish the ordinary valvular sounds.

After taking some brandy and water, she expressed her ability to sit up in bed; and $I$ found that air entered all parts of both lungs.

I told her friends that she was suffering from impcrfect action of the heart, and must be considered in great danger ; but I could not satisfy myself as to the cause of such a sudden attack. She was extremely anxious and unwilling that I should leave her; but I went to procure some stimulants, and she died before my return, having survived the commencement of the attack for three hours. She died quietly, and without convulsions.

A post mortem examination was made twenty hours after death, the body not being quite cold. On opening the thorax, the heart appeared enlarged, this being caused by the distension of the right auricle with frothy blood. The right ventricle contained a small fibrous clot. The other cavities of the heart were empty. The heart itself was healthy; and there was no fluid in the pericardium. The lungs were healthy; but on pressure frotby blood freely issued from the cut surfaces. The stomach and kidneys were healthy; the liver was enlarged, and contained blood mixed with air.bubbles. The uterus was three and a half inches in length, and much congested. The catamenia had appeared the previous day. The left ovary con. 
tained a ruptured Graafian vesicle. There was a fibrous tu- mour of the size of a large pea on the anterior wall of the uterus, and from it sinuses, large enough to allow a full sized pen to enter, passed into the lateral ligaments. On dividing the left lateral ligament, frothy blood escaped, and was traced thence to the heart; but there was none in the left femoral vein, nor in the right common iliac. The brain was not examined.

Remarks. It can scarcely be doubted that the presence of air was the cause of death in this case. Violent vomiting was followed by sudden collapse and speedy death.

Air was traced from the veins of the left lateral ligament to the heart. It must, therefore, either have been generated in the uterus, which is very improbable, both from the suddenness of the attack and the healthy state of that organ; or did violent vomiting during menstruation cause air to enter through an unbroken mucous membrane? However improbable this may appear, it seems the only explanation that can be offered.

CASE III. Mr. W., aged 49, was brought into Reading April 29 th, 185\%, by the county police. He was supposed to be suffering from intoxication; but as he did not recover in a few hours, Mr. Walford was sent for, and found him in a verr depressed condition. It was with difficulty that his name and age could be ascertained from him; and he was quite incapable of giving any account of his illness. The pulse was very small and feeble, and there was a sore on the great toe, apparently the effects of travel. The foot shortly afterwards became swollen; and inflammation extended up the internal saphena vein. There was also inability to empty the bladder; he lin. gered till May 4th, and died from asthenia.

The difficulty in inducing him to speak, and the peculiar slow articulation, although without paralysis, led Mr. Walford to think he might be suffering from softening of the krain, and he requested my assistance at the post mortem examination, which was made twelve hours after death.

The body was much emaciated, but not yet cold; the anterior half of the left foot was much discoloured, and, had the patient lived, would probably have sloughed; from the great toe livid mark extended along the internal saphenous vein to a little above the knee; the whole limb was much swollen, and infiltrated with serum. Bubbles of air were observed to exude on a section of the liver. It seemed so improbable that we should have met with a fourth case of air in the veins, within as many years, that we hesitated to believe the fact, and fancied that compression of the divided liver might have caused air to enter the open mouths of its vessels, more especially as the right side of the heart contained fluid blood without air; but on a more careful examination of the heart, we found air in the coronary vessels. There was a firm fibrinous clot in the right ventricle, extending into the pulmonary artery. The left ventricle was empty, greatly hypertrophied, with much ossific deposit in the aortic valves. We found air in the left internal saphenous vein immediately above the foot, and traced it through the femoral and external iliac veins, and the vena cava inferior. This last was much distended, and collapsed on puncture. The left internal iliac and the veins on the right side were not affected. The left lung was collapsed, and presented a marked contrast to the right, which was much congested, readily breaking down under the finger, but not hepatised. The stomach, intestines, spleen, and kidneys were healthy. The arachnoid was slightly opaque, and the vessels a little distended, but in other respects the brain was healthy. On opening the torcular herophili one bubble of air escaped; but as the lateral sinus had been previously opened, its presence during life cannot be insisted on.

REJaRks. This case resembles one reported by Maisonneuve in 1853 , and called by him gangrène foudroyante. It differs remarkably from those in which air enters suddenly. The duration of the illness, the cerebral condition, with paralysis of the bladder, indicate a poisoned state of the blood, whilst in illness dependent on the presence of air the intellect is usually unaffected. In experiments on animals it has been found that the injection of air causes inflammation of the lungs.

In the cases now narrated, and those published in the Jounnal for June 6 th, examples will be found of most of the effects that can be produced by the injection of air into the veins of animals.

Dr. Cless, of Stutgardt, has collected the particulars of thirteen cases, and alludes to eight others; and it is remarkable that, in six deaths from chloroform, air has been found in the heart. If these facts are correct, we are compelled to admit that air may enter the veins and cause death-

1. During surgical operations.
2. Through the uterine sinuses, especially during or after parturition.

3. From local pathological conditions.

4. As a result of the action of poisons.

\section{CASE OF POISONING BY STRYCHNIA : RECOVERY.}

By J. M. Bryan, M.D., Northampton.

[Read before the South Midland Branch, May 21st, 1857.]

ThE following case occurred in September 1855; and as instances of the kind are rare in practice, $I$ have made a few notes, thinking they might prove interesting. The symptoms were well marked throughout, and perfect recovery took place; the little patient being at the present time perfectly well.

Frank Esson, aged 2, son of Richard and Lucy Esson, St. James's End, Northampton, had been poorly some few days previously to September 20th, 1855 , with bowel complaint; viz. sickness and diarrhœa. In the morning of that day, at half-past eight o'clock, the mother gave him a powder by mistake for another of much the same colour. It was of a light bluish grey colour, and contained in a blue paper. After giving it, she went into a neighbour's house, and was fetched back by her daughter in a few minutes, who said, "Frank could not stand". On seeing him, she thought he had hurt himself, and stat him un in a chair, rubbed his leg, and went into the yard for some water. When she returned, he was quite stiff all over; the stiffness seemed at first to seize his right leg, and then proceeded to the body, arms, face, and jaws; his tongue came out, and was bitten and bloody. She brought him quickly to my house, he being stiff and stretched out all the way, and apparently in strong fits. He was so stiff, that it was not possible to bend him.

As I was from home at the time, Mr. Wm. Daniell, of Newport Pagnell (acting as my assistant), and also some medical friends, attended him. He arrived at 10 A.ss., and was immediately placed in a hot bath in my kitchen, the heat being constantly renewed and kept up until towards 3 P.M. He had a dose of sulphate of zinc given him immediately on his arrival ; and, this not producing vomiting, repeated quantities of mustard and water were given, but no sickness took place. Several doses of castor oil were then given, and two enemata of gruel with castor oil were administered, whereby some motions wer induced. There was great difficulty in giving the castor oil, etc., on account of the great and continued trismus, which was unabated, as was also the tetanus, with arched condition of the body. The case seemed hopeless; and sal volatile, also brandy and water, were administered at intervals. He seemed conscious most of the time, and looked towards his mother when she addressed him. About 3 P.x., he was taken out of the bath, and wrapped in a hot steamed blanket, in which he lay before the fire till 4 P.M., the spasms seeming to become weaker whilst he was in the blanket. Sal volatile was given, and he had some motions, and passed urine. He was quite sensible whenever the paroxysms were off; and occasionally, on their coming on, he said, "mother, it is coming". He was then taken home, and had given to him every four hours small doses of aromatic spirits of ammonia, with spirits of nitrous ether, liquor ammonie acetatis, and camphor mixture.

September 21st. He was somewhat better. The medicine was continued, with the addition of small doses of bicarbonate of potass.

September 22nd. The medicine was continued; and with each dose was given a grain of hydrargyrum cum cretâ and three grains of sugar.

September 25th. A mild tonic medicine was given; and the powders were continued.

September 28th. An aperient was given.

September 29th. I saw him, when he seemed languid, but going on well.

His moutb was completely blistered throughout, and no food was taken till the tenth day, excepting arrow-root; and it was a fortnight before he could stand. After that time he required nursing, and seemed to have extreme general weakness.

The powder given was ascertained to be Battle's vermin killer: the active principle of which is well known to be strychnia. The powder was partially tested by Mr. Harris, chemist, of Northampton, who had no doubt of the presence of strychnia, and found faint traces of it by his first test. 